\title{
Impact of Adoption and Use of Mobile Phone Technology on the Performance of Micro and Small Enterprises in Kisii Municipality Kenya
}

\author{
Rapudo A Onyango, Raymond W. Ongus, Fredrick M Awuor ${ }^{*}$, Constantine Nyamboga \\ Faculty of Information Science and Technology, Kisii University, P.O. Box 408 - Kisii 40200 Kenya \\ *Corresponding Author: fredrickawuor@gmail.com
}

Copyright (C) 2014 Horizon Research Publishing All rights reserved.

\begin{abstract}
The study sought to determine the impact of adoption and use of mobile phone technology on the performance of micro and small enterprises in Kisii municipality, Kenya. The owner's' perception on mobile phone adoption, purpose, sources, factors and perceived effects were studied. The study targeted owners of MSEs in Kisii Municipality. A cross sectional survey research design aimed at identifying MSE owners' perception on the adoption and use of mobile phone technology was used. Stratified sampling was used to identify the MSEs and simple random sampling techniques used to select the respondents and questionnaires placed to collect the data. A questionnaire was used to collect data and a split-half method of estimating reliability used with the aim of assessing the reliability and validity of the research instrument through the expert advice of the supervisors and faculty. The study sample comprised four hundred (400) owners of MSEs out of a population of three thousand five hundred and twenty eight (3528). Once the data had been collected, quantitative data was analyzed using descriptive statistics such as mean, distributions in percentages and frequency counts. Qualitative data was recorded from field data, transcribed and reported in themes and sub themes. Multiple regression analysis was also utilized to assess the relationship among the independent and dependent variables. The study showed among other findings, that there is an impact on adoption and use of mobile phone technology on the performance of micro and small enterprises.
\end{abstract}

Keywords Impact, Adoption, Use, Mobile Phone Technology, Micro and Small Enterprises (MSE's)

\section{Introduction}

Businesses all over the world are getting more interested and involved in strategic management. This has consequences in the way businessmen allocate resources within the firm and influences the competitive advantage of the organization hence the competitiveness and profitability of the firm (Chaffey, 2007). Competitive advantage can only be obtained when the resource adds positive value to the firm; the resource should be unique or rare, be imperfectly imitable and cannot be substituted with another resource (Duncombe and Boateng, 2009). In Kenya there has been a rapidly increasing trend in mobile phone subscription by the rural and urban populations. This increased accessibility to mobile phones has introduced changes in most sectors of the economy and particularly the urban informal sector with Micro and Small Enterprises changing their business and operation environment, thereby creating an impact on Kenya's fastest growing sector and employer (Government of Kenya, 2012).

Mobile Phone Technologies have the potential to improve the economic performance of MSE's affecting almost every structural characteristic of these organizations. With the adoption of this new technological dynamo, its usage is expected to have gained prominence by virtually all MSE's in Kenya. Is there an impact of adoption and use of mobile phone technology among MSE's in Kisii Municipality? The Research problem therefore was to assess the impact of adoption and use of mobile phone technology on the performance of micro and small enterprises in Kisii municipality, Kenya.

The objectives of the study were; to identify the forms of adoption and use of mobile phone technology among MSE's in Kisii Municipality, Kenya, to examine the influence of adoption and use of mobile phone technology among MSE's in Kisii Municipality, Kenya and to examine the relationship between factors influencing the adoption and use of mobile phone technology and performance among MSE's in Kisii Municipality, Kenya. The research sought to answer the following questions (i) what are the forms of adoption and use of mobile phone technology among MSE's in Kisii Municipality, Kenya? (ii) What is the influence of adoption and use of mobile phone technology among MSE's in Kisii Municipality, Kenya? (iii) what is the relationship between 
factors influencing the adoption and use of mobile phone technology and performance among MSE's in Kisii Municipality, Kenya?

\section{Literature Review}

Mobile data technologies are wireless technologies which are built in mobile devices and provide data connection between mobile devices and other devices or networks. The impact of mobile devices in MSEs results from the mobile device functions and mobile data. Mobile data technologies can improve commerce as they are not limited by place and time. Mobile data technologies which "marries" mobile phones and Commerce technologies is seen as eliminating time and distance as barriers for regional businesses in their adoption of these technologies" (Van Akkeren \& Harker, 2002).

Mobile phones are important for development in poor countries because of their ability to bypass the infrastructure barriers in remote/rural areas in Africa. Further, the rapid advancements in technologies and the ease of usage in addition to falling prices of mobile handsets, present the mobile phone as an appropriate and adaptable tool to bridge the digital divide. McCoy and Smith (2007) argue that businessmen in developing countries are welcoming mobile phones as life changing devices. They cite examples of fishermen in India who use the mobile phone to call different markets to inquire about prices; and a hairstylist in Cote d'Ivoire whom the phone provides immediate contact with customers and simplifies the scheduling of customers. In Kenya the introduction of mobile phone banking services such as M-Pesa provide a platform whereby the mobile phone assists operators in the informal sector to complete simple financial transactions since many poor people in Kenya possess mobile phones (Mwaura, 2009).

Although mobile phone adoption studies constitute a significant area of research within the information systems domain (Sakai, 2002), there continues to be a need for better understanding of the factors that drive or inhibit the adoption and use of mobile phone technology within the specific context of MSEs (Giovanni and Mario, 2003; Barua, 2005; Premkumar and Roberts, 2008).Many studies related to MSEs suggest various explanatory variables influencing the adoption of new technologies, such as inter-organizational systems, computerization of businesses, e-commerce, etc. Lack of awareness (Vilaseca, 2003) and cost (Green, 2004) are crucial elements in the general adoption of ICT for MSEs. Lack of awareness contains several factors, which include unfamiliarity of technologies, uncertainty of ICT benefits, and a lack of guidance (Giovanni and Mario, 2003; Barua, 2005; Premkumar and Roberts, 2008). However, cost is mostly related to technology factors including software or information system, training, and maintenance costs. On the other hand, the lack of ICT environment such as e-business infrastructure, technology availability as many studies have found, and critical mass (Ritchie and Brindley, 2005) are major external barriers to obstruct the ICT adoption in MSEs.

Most external barriers come from business related factors. Iacovou et al. (2005) suggest that there are three factors responsible for adoption: external pressures (competitive pressure and requirements by trading partner), perceived benefits of the technology, and organizational readiness. Among them, perceived benefits formed a key reason why participants adopted and continued to use the Internet (Giovanni and Mario, 2003; Barua, 2005; Premkumar and Roberts, 2008). Kirby and Turner (2003) suggest that most adoption frameworks look like a general framework using the external environment, the technology and the capabilities of the organization as its key explanatory variable. Tarafdar's study (2007) suggests that external environments (competitive pressure, government intervention, supplier and buyers) are very critical factors influencing the adoption of Internet commerce. He also points out that organizational and environmental characteristics are required for integrated information systems. Some studies (Ritchie and Brindley, 2005) suggested that, as a primarily external factor of the ICT adoption, the role of government is a very important factor in the ICT adoption.

Most of the roles are related to financial supports such as tax breaks, direct support of the development of application, etc. OECD (2000) mentioned that MSEs need more financing than big enterprises because of the structured characteristics of MSEs: lack of experience, and weakness of market power. Besides, due to the development of a variety of ICT and the proliferation of ASPs, ICT outsourcing is emerging as an influencing factor and becoming suitable for many MSEs sectors (Vilaseca, 2003).

The cost of adoption is an important factor in the adoption and use of mobile phone technology (Muraya, 2006). The MSEs will less likely adopt mobile phone technology when its initial set-up cost is high (Dixon et al, 2002). Poon \& Swatman (2006) and Reynolds (2004) stated that small businesses often have difficulty in obtaining financial resources. Any new technology like mobile phone technology may be considered too expensive to many MSEs because of their lack of financial resources (Poon and Swatman, 2006). Tidd (2007) expressed that MSEs face specific problems in the formulation of their innovation strategies due to their limited resources and range of technological competencies.

Paul and Pascale (2003) study reveals that the mobile phone adoption in MSE depends on the owner being the decision-maker. Their findings clearly indicated that Mobile Phone Adoption is positively related to firm size. It is very important for organization to determine its employee's knowledge or skills of ICT because knowledge or previous experiences may influence organization decision in adopting mobile phone technology. The ability of the owner in ICT's knowledge or skills is definitely increasing the opportunity of mobile phone technology use amongst MSEs. Reynolds (2004) found that MSE owners are unlikely to adopt more sophisticated technologies if they are not familiar with the 
basic ones. This is because of the limited number of employees with lack of technical knowledge. This lack of knowledge based employees might hinder or prevent technology adoption if the owner believes that this technology can only be employed using specialist staff (Reynolds, 2004). External pressure from business trading partners is one of the important predictor that has strong influence on adoption of mobile phone technology with lack of pressure from their trading partners, the business owner may perceive the technology as a waste of resources (Thong and Yap, 2005; Iacovau et al, 2005). This means that MSEs trading partners are not fully utilizing mobile phone technology in doing business. According to Kirby and Turner (2003) dependency on customer/supplier is closely related to 'external pressure to adopt. When a major supplier or customer adopts mobile phone technology, the MSE owner is more likely to adopt (Kirby and Turner, 2003). Parker (2007) and Poon and Swatman (2006) studies, found that MSEs are often forced to use mobile phone technology by large companies. So this could be a factor driving the use of mobile phone technology if their trading partners force them to use it.

In a more recent study, Seyal et al. (2007) found that management support, government support, and perceived benefits are significant predictors that influenced MSEs in Brunei to adopt mobile phone technology. Regarding mobile phone technology adoption in Taiwan, Lindner \& Bagherzadeh (2004) identifies these determinants as having influence on adoption: organizational size, CEOs' characteristics, and CEOs' perception of relative advantage, compatibility, and complexity. Ndubisi and Jantan (2003), in evaluating information system use among medium and small--sized firms in Malaysia, found that computing skills and technical backing are strong anchors of the perception of usefulness and also wield direct influence on system use. In another study conducted by Ndubisi and Kahraman (2005), they find that the use of advanced systems is significantly related to innovativeness, and suggest that innovativeness is an important trait in determining mobile phone technology use among women entrepreneurs in Malaysia.

The schematic diagram above was used to show the relationship between the independent and dependent variables. Essentially, the conceptual framework shown is the foundation on which the entire research is based upon. Performance of MSEs is the dependent variable in this research. The independent variables are analyzed in this research in order to find out the answer or solution to the problem i.e. impact of adoption and use of mobile phone technology on the performance of micro and small enterprises. In this situation, the study has independent variables i.e. forms of mobile phone adoption and use and factors of mobile phone adoption and use that are believed to have influences on the independent variable.

\section{Research Methodology}

The study employed a cross sectional survey research design whereby the researcher studied perceptions and responses as held by the respondents. A cross sectional research design is a present oriented methodology used to investigate populations by selecting samples to analyze and discover occurrences at a particular point in time. It provided quantitative descriptions of some part of the population (Trochim, 2006).

The study was carried out among MSEs found in Kisii Municipality and the study population consisted of 3528 owner-managers of MSEs within Kisii. The owners were from varied backgrounds since the municipality has people from many different ethnic groups and the businesses are varied (community, social and personal service activities, construction, manufacturing, real estate and renting, hotels and restaurants, transport, storage and communications, wholesale \& retail).

Yamane (1967) provided a simplified formula to calculate sample sizes when the population under study is less than ten thousand. This formula was used to calculate the sample sizes as shown below.

$$
\begin{gathered}
n=\frac{N}{1+N e^{2}} \\
\text { Where } ; n=\begin{array}{l}
\text { is the sample size, } \\
\mathrm{N}=\text { is the population size, and } \\
\mathrm{e}=\text { level of precision. A } \\
\text { confidence level and }
\end{array}
\end{gathered}
$$$$
\mathrm{e}=\text { level of precision. A } 95 \%
$$

From the above computation, the sample size for the study was derived as follows

$$
n=\frac{3528}{1+3528\left(0.05^{2}\right)}=399.88 \approx 400
$$

The study used a $95 \%$ confidence level, this meant that if the same population was sampled on numerous occasions and interval estimates are made on each occasion, the resulting intervals would bracket the true population parameter in approximately $95 \%$ of the cases and $\mathrm{P}=0.5$ which means that the probability of the difference having happened by chance is 0.5 in 1 .

Both stratified and simple random sampling techniques were used for the study. Stratified sampling ensured that the sub-groups of MSEs were proportionally represented and that the difference in the sub-group characteristics was accounted for. Simple random sampling was used to ensure that each member of the target population has an equal chance of being included in the sample (Koul, 2002).

The study used a structured questionnaire to collect primary quantitative data from the owners of each of the selected MSEs. The questionnaire was developed to capture information on owner's knowledge on the principles of adoption and use of mobile phone technology. The Questionnaire was used because it offers a considerable advantage in administration, it also presents a stimulus potential to large numbers of people simultaneously and provide the investigator with an easy way of gathering data (Orodho and Kombo, 2002). 
Content validity of the research instruments was done to ensure that the instrument gathered the information the study purports to collect. According to Gay (2005), content validity is determined by expert judgment. Therefore the researcher relied on the expert advice of the supervisors and other members of the Faculty of Information Science and Technology - Kisii University on the validity of the instruments. The questionnaire was also piloted in Nyamira Municipality outside the area of study to test reliability. Pilot testing was conducted to detect if there are weaknesses in design and instrumentation and to provide proxy data for selection of an appropriate sampling design. Measurement of reliability provided consistency for the measurement of variables (Zhang et al., 2000). Cronbach alpha was the basic formula used for determining the reliability based on internal consistency (Gay, 2005)

Data analysis on collected field data was done along the research objectives. The researcher conducted data cleaning by inspecting data to identify any mistakes or any other wrongly answered or unresponded to items. Data was then sorted, edited, classified, coded and tabulated. Quantitative methods including the use of percentages, frequency distributions, tables and multiple correlations. The process of data collection was guided by the ethical considerations of confidentiality, anonymity, responsibility, respect, competence, consent, security and understanding.

\section{Results and Discussion}

The demographic that were considered for this study were Gender, Age, Level of Education and type of MSE. It was established that a $64.75 \%$ of the respondents were male while $34.4 \%$ were females. Both groups had at least a $30 \%$ representation in the study. In relation to age it was established that $33.98 \%$ of the respondents were between the ages $31-40$ years and that they were Male. $34.75 \%$ of the respondents were between the ages $20-30$ years and that they were female. Only $5.02 \%$ was above 50 years old and male, while $6.38 \%$ were females in the same age bracket. Thus the majority of the respondents were 50 years and below.

$66.41 \%$ of the respondents were male MSE owners with Secondary Level of Education while $63.12 \%$ were females with Secondary Level of Education, $25.10 \%$ of the respondents were males with college Level of Education while $31.21 \%$ were females in the same bracket. Of the remaining $5.02 \%$ of the male respondents were degree holders and $2.13 \%$ of the females were also degree holders. Majority of the respondents had Secondary level education although very few of them had graduate level of education.

According to table 4.4 above $35.14 \%$ of the respondents were males in the Wholesale \& Retail business and 25.53\% were females in the same business whereas the remaining $8.49 \%$ of the respondents were males in the Transport and communications sector within the municipality. It is evident that while the highest percentages of the respondents were males from wholesale and retail sectors; the least females were females from Real estate and Renting. In order to answer the first objective, the study sought to find out forms adoption and use of Mobile Phone Technology. All the respondents indicated that they had adopted and use of Mobile Phone Technology It was therefore be concluded that adoption and use of Mobile Phone Technology was evident in MSE in Kisii municipality.

The study further noted that voice communication was the most important function for MSEs contacting employees, suppliers and customers, $98.46 \%$ males and $85.11 \%$ female respondents used voice communication in their businesses. About $89.19 \%$ males and $56.03 \%$ female respondents used Mobile Money transfers to contact suppliers. Around $40.54 \%$ males and $73.05 \%$ female respondents used SMS to contact employees and customers. Only $22.39 \%$ males and $31.21 \%$ female respondents used the mobile phone as Storage Memory for suppliers. About $13.51 \%$ males and $7.80 \%$ female respondents used their Mobile Phones for Remote Computing. Electronic Payments was used by $45.95 \%$ males and $43.97 \%$ female respondents as a form of adoption and use $20.85 \%$ males and $8.51 \%$ female respondents used their mobile phone as a source of business contacts. Only $21.62 \%$ males and $10.64 \%$ female respondents used Internet and Data services with their mobile devices $5.41 \%$ males and $13.48 \%$ female of the respondents stated their use of mobile phones for Mobile Banking while $9.27 \%$ males and $6.38 \%$ female respondents relied on their mobile phones as a tool for marketing their services. Majority of the respondents used voice communication as a form of adoption while mobile banking was the least form adopted.

In order to meet this second objective, the factors were categorized into five parts namely; Benefits of Adoption of Mobile Phone Technology, Cost of Adoption of Mobile Phone Technology, Impacts of Technology of Adoption of Mobile Phone Technology, External Environment of Adoption of Mobile Phone Technology, and Government Support of adoption of Mobile Phone Technology. In Each part the respondents were asked to indicate which of them best expressed the perceived factor of adoption and use. The results are shown in Table 1 below: 
Table 1. Influence of Adoption of Mobile Phone Technology

\begin{tabular}{|l|c|c|c|c|c|}
\hline & $\mathrm{SD}$ & $\mathrm{D}$ & $\mathrm{U}$ & $\mathrm{A}$ & $\mathrm{SA}$ \\
\hline $\begin{array}{l}\text { Benefits Mobile Phone } \\
\text { Technology }\end{array}$ & $65(16.15 \%)$ & $51(12.65 \%)$ & $41(10.35 \%)$ & $70(17.55 \%)$ & $173(43.30 \%)$ \\
\hline $\begin{array}{l}\text { Cost of Mobile Phone } \\
\text { Technology }\end{array}$ & $65(16.15 \%)$ & $66(16.55 \%)$ & $57(14.35 \%)$ & $72(18.00 \%)$ & $140(34.95 \%)$ \\
\hline $\begin{array}{l}\text { Impacts of Mobile Phone } \\
\text { Technology }\end{array}$ & $60(15.10 \%)$ & $45(11.35 \%)$ & $74(18.55 \%)$ & $61(15.30 \%)$ & $159(39.70 \%)$ \\
\hline $\begin{array}{l}\text { External Environment of } \\
\text { Adoption }\end{array}$ & $61(15.20 \%)$ & $51(12.65 \%)$ & $74(18.40 \%)$ & $159(39.65 \%)$ & $56(14.10 \%)$ \\
\hline $\begin{array}{l}\text { Government Support for } \\
\text { Mobile Phone Technology }\end{array}$ & $54(13.40 \%)$ & $45(11.30 \%)$ & $53(13.35 \%)$ & $97(24.15 \%)$ & $151(37.80 \%)$ \\
\hline
\end{tabular}

Key : $\quad \mathrm{SA}=$ Strongly Agree; $\mathrm{A}=$ Agree; $\mathrm{U}=$ Undecided; $\mathrm{D}=$ Disagree; $\mathrm{SD}=$ Strongly Disagree

According to Table $1,43.30 \%$ of the respondents strongly agreed benefits of use is one of the factors of adoption and use of mobile phone technology, while $10.35 \%$ of the respondents were undecided. Cost of mobile phone was indicated by $34.95 \%$ as a factor of adoption and use of mobile phone technology, $16.55 \%$ of the respondents disagreed. $39.70 \%$ of the respondents felt that impact of adoption was a factor; in this group $11.35 \%$ disagreed. In addition $39.65 \%$ of the respondents agreed that the external environment was a factor of technology of adoption and use of mobile phone technology, while $12.65 \%$ disagreed with that opinion $37.80 \%$ of the respondents agreed that government support was a factor of adoption and use of mobile phone technology $11.30 \%$ of the respondents disagreed. It is evident that most of the respondents agree that factors of adoption such as benefits of adoption of mobile phone technology, cost of adoption of mobile phone technology, impacts of technology of adoption of mobile phone technology, external environment of adoption of mobile phone technology, and government support of adoption of mobile phone technology help in adopting mobile phone technology.

The study further sought to determine the factors that influence use of mobile phone technology. In order to meet this objective, the factors were categorized into five parts namely; Perceived usefulness, perceived advantage, perceived value, perceived image and perceived risk. In Each part the respondents were asked to indicate which of them best expressed the perceived factor of use. The findings are recorded in the Table 2 below

Table 2. Influence of Adoption of Mobile Phone Technology

\begin{tabular}{|l|c|c|c|c|c|}
\hline & SD & D & U & A & SA \\
\hline Perceived Usefulness & $50(12.50 \%)$ & $44(11.00 \%)$ & $60(15.00 \%)$ & $106(26.45 \%)$ & $140(35.05 \%)$ \\
\hline Perceived Advantage & $51(12.70 \%)$ & $48(12.05 \%)$ & $75(18.70 \%)$ & $80(20.05 \%)$ & $146(36.50 \%)$ \\
\hline Perceived Value & $66(16.60 \%)$ & $54(13.40 \%)$ & $61(15.15 \%)$ & $84(20.90 \%)$ & $136(33.95 \%)$ \\
\hline Perceived Image & $62(15.50 \%)$ & $50(12.40 \%)$ & $59(14.75 \%)$ & $146(36.50 \%)$ & $83(20.85 \%)$ \\
\hline Perceived Risk & $65(16.15 \%)$ & $51(12.65 \%)$ & $41(10.35 \%)$ & $70(17.55 \%)$ & $173(43.30 \%)$ \\
\hline
\end{tabular}

Key : $\quad \mathrm{SA}=$ Strongly Agree; $\mathrm{A}=$ Agree; $\mathrm{U}=$ Undecided; $\mathrm{D}=$ Disagree; $\mathrm{SD}=$ Strongly Disagree

According to Table 2, $35.05 \%$ of the respondents strongly agreed perceived usefulness by is one of the factors of use of mobile phone technology, while $11.00 \%$ of the respondents disagreed. Perceived advantage was indicated by $36.50 \%$ as factor for use of mobile phone technology, $12.05 \%$ of the respondents disagreed. $33.95 \%$ of the respondents felt that perceived value was a factor; in this group $15.15 \%$ were undecided. In addition $36.50 \%$ of the respondents expressed that perceived image was a factor of use of mobile phone technology, while $12.40 \%$ strongly disagreed with that opinion. $43.30 \%$ of the respondents strongly agreed that perceived risk was a factor of mobile phone technology, $10.35 \%$ of the respondents were undecided. From the responses it is evident that perceived usefulness, perceived advantage, perceived value, perceived image and perceived risk are factors associated with use of mobile phone technology

The third objective of this study sought to measure the relationship between factors influencing the adoption and use of mobile phone technology and performance. Correlation analysis was carried out to examine the extent to which facet variables (Benefits of Adoption \&Use, Cost of Adoption \& Use, Impacts of Technology, External Environment and Government Support) predict firm performance. Table 3 summarizes the regression coefficients of performance and its determinants. Multiple Correlations analysis was carried out to examine the extent of mobile phone technology variables on performance. The following formulae was used.

$$
\mathrm{y}=\beta 0+\beta 1 \mathrm{x} 1+\beta 2 \mathrm{x} 2+\ldots+\beta \mathrm{kxk}+\varepsilon .
$$

Where 


$\begin{aligned} \mathrm{Y} & =\text { the value of the Dependent variable } \\ \beta 0 & =\text { y-intercept or constant, } \\ \beta 1 & =\text { the coefficient on the first predictor variable, } \\ \beta 2 & =\text { is the coefficient on the second predictor variable } \\ \beta 3 & =\text { is the coefficient on the third predictor variable } \\ \beta 4 & =\text { is the coefficient on the fourth predictor variable } \\ \beta 5 & =\text { is the coefficient on the fifth predictor variable } \\ \varepsilon & =\text { is the error term or residual that can't be explained by the model. }\end{aligned}$

Table 3. Multiple Correlation Analysis on Adoption of Mobile Technology

\begin{tabular}{|c|c|c|c|c|c|}
\hline \multirow[t]{2}{*}{ Model 1} & \multicolumn{2}{|c|}{$\begin{array}{c}\text { Unstandardized } \\
\text { Coefficients }\end{array}$} & \multicolumn{3}{|l|}{$\begin{array}{c}\text { Standardized } \\
\text { Coefficients }\end{array}$} \\
\hline & $\mathrm{B}$ & Std. Error & Beta & $\mathrm{t}$ & Sig. \\
\hline (Constant) & 1.813 & .043 & & 42.285 & .000 \\
\hline Benefits of Adoption & .402 & .052 & .618 & 7.725 & .000 \\
\hline Cost of Adoption & .024 & .051 & .037 & .480 & .631 \\
\hline Impacts of Technology & -.059 & .102 & -.087 & -.574 & .566 \\
\hline External Environment & .233 & .105 & .348 & 2.212 & .028 \\
\hline Government Support & .030 & .053 & .043 & .554 & .580 \\
\hline \multicolumn{6}{|c|}{ Dependent Variable: Performance } \\
\hline \multicolumn{6}{|l|}{$\mathrm{R}=.975$} \\
\hline \multicolumn{6}{|l|}{$\mathrm{R} 2=.951$} \\
\hline \multicolumn{6}{|l|}{ Adjusted $\mathrm{R}^{2}=.948$} \\
\hline $\mathrm{Sig}=0.000$ & & & & & \\
\hline
\end{tabular}

Table 3 provided the $\mathrm{R}, \mathrm{R}^{2}$ and the Adjusted $\mathrm{R}^{2}$; the table was used to determine how well correlation analysis fits the data on adoption of mobile phone technology. The value of 0.975 indicated a good level of prediction. It is deduced from the value of 0.975 that our independent variables explain $97.50 \%$ of the variability of the dependent variable (performance). An $\mathrm{R}^{2}$ of $0.951(95.1 \%)$ indicated that the regression line perfectly fitted the data used for the study. The adjusted $\mathrm{R}^{2}$ value of 0.948 (94.8\%) indicated how well the independent predicted the dependent variable. The regression model was significant and thus reliable for making conclusions and recommendations (Sig. <.05). The most Significant predictors of performance were

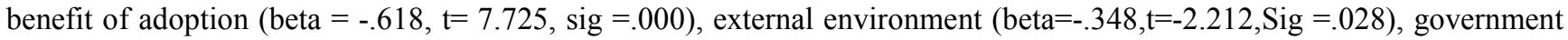
support (beta $=-.043, \mathrm{t}=-0.554, \mathrm{Sig}=.580$ ), whereas cost of adoption (beta $=.037, \mathrm{t}=0.480, \mathrm{Sig}=.631$ ), and impacts of technology (beta=.-.087,t=-.574, sig =.566). The results revealed that all the factor components of adoption of mobile phone technology (benefits of adoption cost of adoption, impacts of technology, external environment and government support) were significant predictors of performance.

Multiple Correlations analysis was carried out to examine the extent of mobile phone technology variables on performance. 
Table 4. Multiple Correlation Analysis on Use of Mobile Technology

\begin{tabular}{|c|c|c|c|c|c|}
\hline \multirow[t]{2}{*}{ Model 2} & \multicolumn{2}{|c|}{$\begin{array}{c}\text { Unstandardized } \\
\text { Coefficients }\end{array}$} & \multirow{2}{*}{$\begin{array}{c}\text { Standardized } \\
\text { Coefficients } \\
\text { Beta } \\
\end{array}$} & \multirow[b]{2}{*}{$\mathrm{t}$} & \multirow[b]{2}{*}{ Sig. } \\
\hline & $\mathrm{B}$ & Std. Error & & & \\
\hline (Constant) & 1.794 & .044 & & 40.486 & .000 \\
\hline Perceived Usefulness & -.096 & .060 & -.133 & -1.590 & .113 \\
\hline Perceived Advantage & .308 & .078 & .437 & 3.929 & .000 \\
\hline Perceived Value & .160 & .059 & .238 & 2.724 & .007 \\
\hline Ease of Use & -.273 & .085 & -.404 & -3.195 & .002 \\
\hline Perceived Risk & .534 & .050 & .821 & 10.711 & .000 \\
\hline \multicolumn{6}{|c|}{ Dependent Variable: Performance } \\
\hline \multicolumn{6}{|l|}{$\mathrm{R}=.968$} \\
\hline \multicolumn{6}{|l|}{$\mathrm{R} 2=.938$} \\
\hline \multicolumn{6}{|l|}{ Adjusted R2 $=.934$} \\
\hline $\operatorname{sig}=0.000$ & & & & & \\
\hline
\end{tabular}

Table 4 provided the $\mathrm{R}, \mathrm{R}^{2}$ and the Adjusted $\mathrm{R}^{2}$; the table was used to determine how well correlation analysis fits the data on adoption of mobile phone technology. The $\mathrm{R}$ value of 0.968 indicated a good level of prediction. It is deduced from the value of 0.968 that our independent variables explain $96.80 \%$ of the variability of the dependent variable (performance). An $\mathrm{R}^{2}$ of 0.938 (93.8\%) indicated that the regression line perfectly fitted the data used for the study. The adjusted $\mathrm{R}^{2}$ value of 0.934 (93.4\%) indicated how well the independent predicted the dependent variable. The regression model was significant and thus reliable for making conclusions and recommendations (Sig. <.05). The most Significant predictors of performance were perceived risk (beta $=-.821, \mathrm{t}=10.711$, sig $=.000$ ), perceived advantage (beta $=-.437, \mathrm{t}=-3.929, \mathrm{Sig}=.000$ ), perceived ease of use (beta $=-.404, \mathrm{t}=-3.195, \mathrm{Sig}=.002$ ), whereas perceived value (beta $=-.238, \mathrm{t}=-2.724, \mathrm{Sig}=.007$ ), and Perceived Usefulness (beta $=.-.133, \mathrm{t}=-1.590, \mathrm{sig}=.113$ ). The results as shown in table 4.18 revealed that all the factor components of adoption of mobile phone technology (perceived usefulness, perceived advantage, perceived value, perceived ease of use and perceived risk) were significant predictors of performance.

The study showed that adoption and use of Mobile phone technology is on the rise among MSE's in Kisii municipality. Moreover, the study suggests that factors such as Benefits of Adoption \&Use, Cost of Adoption \& Use and Government Support are important factors for adoption and use of Mobile phone technology. Studies that have been done on Mobile phone technologies in the informal sector have focused mainly on the internet and computer usage rather than on applications of a mobile phone, and yet the mobile phones are wide used in the informal sector for business transactions. Therefore, in this study the researcher confirmed that for the adoption and use of Mobile phone technology to be spread out the government needs to put in place intervention measures and that they MSE should be involved in such measures.

\section{Conclusions and Recommendations}

The findings of this study show that there is impact of adoption and use of mobile phone technology on the performance of micro and small enterprises In Kisii Municipality, Kenya considering that well over half of the MSEs who participated in this study had adopted and used mobile phone technology. Contrary to the general belief, female MSE owners were also involved in mobile phone technology adoption like their male counterparts. This is a unique finding unlike other findings of researchers on mobile phone technology that only male MSE owners get involved in mobile phone technology. The adoption and use play an important role in increasing the awareness of the huge potentialities of Mobile Phone Technology; in this owners acquire a culture integrating Mobile Phone Technology g in their work activities and understanding in depth the potentialities of these tools (Magretta, 2002).

Based on the first objective i.e. forms of adoption and use of mobile phone technology among MSE's in Kisii Municipality, the findings of the study identified various forms of mobile phone technology as being internet and data services, memos / reminders, mobile banking, electronic payments, mobile money transfers, marketing services, voice communication, business contacts, remote computing and storage memory. Aminuzzaman et al. (2003) confirms this from the international trend that mobile phone is still mostly a device for communication for MSE Owners. It is used for making phone calls and sending SMS daily or at least weekly, utility services in general were popular in current use.

Based on the second objective i.e. the influence of adoption and use of mobile phone technology among MSE's in Kisii Municipality, the findings indicated influences of adoption and use of mobile phone technology. Many of the MSE owners who participated in the study expressed that there were benefits to adoption namely; faster response to customers needs, increased internal efficiency, keep up with competitors, access to new markets and lower operational 
costs. other factors stated by the MSE owners included difficulty in obtaining financial resources, lack of financial resources, mobile phone accessories, hardware and software and maintenance costs and security. They also expressed that lack of skills amongst owners to use, lack of technical knowledge by owner, lack of software usage knowledge, preparedness to adopt new technologies and dangers of job loss led to their adoption and use of mobile phone technology.

Based on the third objective i.e. the relationship between factors influencing the adoption and use of mobile phone technology and performance among MSE's in Kisii Municipality, MSE Owners who participated in the study were satisfied with their adoption of Mobile phone technology. The multiple correlation analysis findings revealed a Significant and positive relationship between mobile phone adoption and firm performance which suggested that when MSEs have considered benefits of adoption, cost of adoption, impact of technology, external environment and government support it enhances their performance. According to Mungunasi (2000), the customer perspective of newness necessitates a change in consumer behavior to accommodate new product usage conditions.

On the other hand, for mobile phone use the MSEs need to operationalize various attributes so as to develop competitive advantage, these may include strengthening social networks; increase people's ability to deal with emergencies and to work together thereby reducing costs and increasing productivity (Woodside, 2005). Fink \& Kraus (2009) contend that mobile phone use is associated with usefulness, competitive advantage, value, image and risk. To realize the benefits of mobile phone use an MSE would pursue innovative imitation of competitors' products, new product invention, and improvement or modification of the existing products (Kundu \& Katz, 2003).

The conclusion of the study was made in accordance with the study objectives as follows: The study shows that there is an influence of adoption and use of mobile phone technology among MSE's through faster response to customers' needs, increased internal efficiency, access to new markets and lower operational costs $t$ are Significant elements of mobile phone adoption and use. The findings further revealed a positive relationship between mobile phone adoption and firm performance which implied that when MSEs possess the benefits of adoption, cost of adoption, impact of technology, external environment and government support, they enhance their performance. This is confirmation that MSEs' willingness to embrace use of mobile phones during their work processes would have positive effect on the performance of MSEs. From the findings a Significant and positive relationship between mobile phone use and firm performance was revealed which is indication that the more the MSEs were willing and prepared to learn through with usefulness, competitive advantage, value, image and risk, this would improve their governance structures, processes and competences. This suggests that for the MSEs to become more innovative in their work processes there was need for them to use mobile phone adoption as this would enhance their competitiveness. The higher the level of use of mobile phone among MSEs the likelihood that the MSEs will remain competitive this volatile

As a result of the findings obtained from the study the following are recommended. The Government through the ministries of Trade and, Information and Communication should initiate and support training programmes to develop the capacity of small and medium entrepreneurs in mobile phone technology tools. Seminars or induction sessions should be created by stakeholders to allow MSEs to evaluate new inventions. Stakeholders should make deliberate programmes to create awareness on the utility of mobile phone technologies in MSEs. MSEs should start investing in basic mobile phone technology tools to help improve their business management practices in line with global trends. This will make them more competitive and help access global markets. Government agencies could establish a close link with all MSEs and get continuous feedback from them in order to identify problem areas and take necessary actions to rectify them and there is need to finalize and formalize policies along with the required legislation for effective implementation. This should go beyond general policy provisions by including pro-active policy interventions, designing an elaborate incentive package for investments, and entrenching competition and technology transfer.

Findings have drawn conclusions about the adoption and use of the mobile phone technology in MSEs and have laid a foundation on which further longitudinal studies should be undertaken. The agenda for further research should include a study of more MSE practices with regard to their business models and their effects on adoption. Future study should be on types of ICT applications adopted by MSEs and their respective impacts on businesses. In addition, future research may examine the knowledge and understanding of MSEs of government's enforcement on ICT laws.

\section{REFERENCES}

[1] Aminuzzaman, S., Baldersheim, H., \& Jamil, I. (2003). Talking back! Empowerment andmobile phones in rural Bangladesh: A study of the village phone scheme of Grameen Bank. Contemporary South Asia, 12(3), 327-348. doi:10.1080/0958493032000175879

[2] Barua, A., Kriebel, C.H. \& Mukhopadhyay, T (2005). Information Technologies and business value: An analytic and empirical investigation. Information Systems Research, 6(1), 3-23.

[3] Chaffey D. (2007). E-Business and E-Commerce Management. Pearson Education Limited. Third edition 2007, Essex CM20 2JE, England.

[4] Dixon, T., Thompson R. and McAllister, P. (2002). The Value of ICT for MSEs in the UK: A Critical Literature Review, College of Estate Management, Reading. 
[5] Duncombe, R. and Boateng, R. (2009). What Every Business Student Needs to Know About Information Systems. Communications of the Association for Information Systems, 9, 467-477.

[6] Fink M., Harms R., Kraus S. (2009): Selbstverpflichtung als Erfolgsfaktor bei kooperativer Internationalisierung junger Unternehmen. Zeitschrift für Betriebswirtschaft, special issue 1, pp. 107-132.

[7] Gay, L. R. (2005). Educational research: Competencies for analysis and application (7th ed.). Upper Saddle River, NJ: Pearson Education.

[8] Giovanni F. \& Mario, A. (2003). Small company attitude towards ICT based solutions: some key-elements to improve it. Educational Technology \& Society, Hershey, PA: Idea Group Publishing Guthrie

[9] Government of Kenya (2012). Development of Micro and Small Enterprises for Wealth and Employment Creation for Poverty Reduction. Sessional Paper No 2 of 2005. Nairobi: Government Printer.

[10] Green, N. (2004). Personas of E-commerce adoption in small businesses in New Zealand, Journal of Electronic Commerce in Organizations, Vol. 4(3) pp.17-45

[11] Iacovou, C. L., I. Benbasat, et al. (2005). Electronic Data Interchange and Small Organizations: Adoption and Impact of Technology. MIS Quarterly 19(4), 121-163.

[12] Kim, W. G., and Cha, Y. (2002), "Antecedents and Consequences of Relationship Quality in Hotel Industry", International Journal of Hospitality Management, Vol. 21 No. 4, pp. 321-338.

[13] Kirby, D. \& Turner, M. (2003). IT and the small retail business. International Journal of Retail and Distribution Management, 21 (7), 20-27.

[14] Koul, K. K. Y. (2002). Case Study Research: DeSign and Methods, 2nd edn, Vol. 5. Sage Publications, Thousand Oaks, CA.

[15] Kundu, S.K. \& Katz, J.A. (2003). Born-international SMEs: BI-level impacts of resources and intentions. Small Business Economics.

[16] MacGregor V., Morris, M. G., Davis, G. B., \& Davis, F. D. (2008). User acceptance of information technology: Toward a united view. MIS Quarterly, 273, 425-478

[17] Magretta, J. (2002), "Why business models matter", Harvard Business Review, Vol. 80 No. 5, pp. 86-92.

[18] McCoy, J. and Smith, G. (2007). Mobile end-user service adoption studies: A selective review. Scandinavian Journal of Information Systems, 14, 301-358

[19] Mungunasi, E. (2000). Survey of information and communication technologies within small, micro and medium enterprises in Tanzania. Washington, DC: World Bank.

[20] Muraya, P. (2006). Urban Planning and Small-Scale Enterprises in Nairobi Kenya. Habitat International, Vol. 30 (1) $127-143$

[21] Mwaura, P. W. (2009). Networks, Information and Small Enterprises: New Technologies and the Ambiguity of Entrepreneurs, Information Technology for Development,
Vol. 10(4) 221 - 232.

[22] Orodho, A.J. and Kombo D.K (2002). Research Methods. Nairobi : Kenyatta University, Institute of Open Learning.

[23] Parker, O. (2007). Exploring the Usage and Impact of "Transformational" Mobile Financial Services: The Case of M-PESA in Kenya. Journal of Eastern African Studies, 3, 3, 509-525.

[24] Paul, D and D. Pascale (2003). Information Technology and Economic Development: An Introduction to the Research Issues, Research Paper, 153, World Institute for Development Economics Research, Sage, Los Angeles, CA

[25] Poon S. and Swatman P. (2006). An Exploratory Study of Small Business Internet Commerce Issues, Information and Management, 35, 9-18.

[26] Premkumar, G., \& Roberts, M. (2008). Adoption of new information technologies in rural small businesses. Omega, The International Journal of Management Science, 27(4), 467-484

[27] Reynolds, P. (2004). Your Own Business: A Practical Guide to Success, McGraw Hill, New York, NY.

[28] Ritchie, B. and Brindley, C (2005). ICT adoption by MSEs: Implications for relationships and management, New Technology, Work and Exployment, Vol. 20, No. 3, 205-217.

[29] Sakai, K. (2002). Enhancing Manufacturing Performance with ERP Systems. Information Systems Management, 17(3), $1-13$.

[30] Thong, J.Y. and Yap, C.S. (2005). CEO characteristics, organizational characteristics and information technology adoption in small business, Omega International Journal of Management Science, Vol. 23 (4) 429-42.

[31] Tidd, J. (2007). Managing Innovation: integrating technological, market and organizational change, Chichester : John Wiley \& Sons,

[32] Trochim M. K. (2006). Research Methods Knowledge Base by Web Center for Social Research Methods, London: Routledge.

[33] Van Akkeren, J., \& Harker, D. (2002). Mobile data technologies and SME adoption and diffusion: An empirical study on barriers and facilitators. Australasian Journal of Information Systems, 9(2), 1-16.

[34] Vilaseca, J. (drtor.) (2003). Las TIC y las transformaciones de la empresa catalana, Barcelona: Foundation for the Open University of Catalonia

[35] Woodside, M. (2009). Introduction to human services (6th ed.) Pacific Grove, CA: Brooks/Cole/Thomson Learning.

[36] Yamane Taro (1967). Designing and Conducting Survey Research - A Comprehensive Guide, Jossey-Bass Publishers, San Francisco.

[37] Zhang, Z., Waszink, Ab. \& Wijngaard, J. (2000). An instrument for measuring TQM implementation for Chinese manufacturing companies. International Journal of Quality and Reliability Management, 17(7), 730-755. 